\title{
Big volcano science: needs and perspectives
}

\author{
Paolo Papale $^{1}$ (D) $\cdot$ Deepak Garg ${ }^{1}$
}

Received: 14 July 2021 / Accepted: 4 January 2022 / Published online: 12 February 2022

(c) The Author(s) 2022

\begin{abstract}
Volcano science has been deeply developing during last decades, from a branch of descriptive natural sciences to a highly multi-disciplinary, technologically advanced, quantitative sector of the geosciences. While the progress has been continuous and substantial, the volcanological community still lacks big scientific endeavors comparable in size and objectives to many that characterize other scientific fields. Examples include large infrastructures such as the LHC in Geneva for sub-atomic particle physics or the Hubble telescope for astrophysics, as well as deeply coordinated, highly funded, decadal projects such as the Human Genome Project for life sciences. Here we argue that a similar big science approach will increasingly concern volcano science, and briefly describe three examples of developments in volcanology requiring such an approach, and that we believe will characterize the current decade (2020-2030): the Krafla Magma Testbed initiative; the development of a Global Volcano Simulator; and the emerging relevance of big data in volcano science.
\end{abstract}

Keywords Volcano science $\cdot$ Magma $\cdot$ Krafla Magma Testbed $\cdot$ Global Volcano Simulator $\cdot$ Big volcano data

\section{Introduction}

Volcano science has deeply evolved during last decades. One of us (PP) presented perspectives for next decade developments at the American Geophysical Union (AGU) Fall Meetings 2010 and 2020, which are summarized in Table 1. As from that easy forecast, approaches based on statistics and probabilities have become progressively more widespread in volcanology: a search in the Web of Science shows that the number of entries responding to "volcano" and "probability" more than doubles from the first to the second decade of this century. Similarly, sharing resources, as well as sharing experience, is continuing to increase in relevance. Examples include the large investments from the European Commission in infrastructural developments such as EPOS, the European Plate

Editorial responsibility: F. Sigmundsson

This paper constitutes part of a topical collection: Looking Backwards and Forwards in Volcanology: A Collection of Perspectives on the Trajectory of a Science.

Paolo Papale

paolo.papale@ingv.it

1 Istituto Nazionale Di Geofisica E Vulcanologia, Sezione Di Pisa, Via Cesare Battisti 53, 56125 Pisa, Italy
Observing System (www.epos-eu.org), representing the platform for EU-level data accessibility and sharing in solid Earth, and the frame within which European geoscientists discuss and implement common development strategies; and other EU-level investments, facilitated through EPOS, aimed at transverse, transnational access to resources such as advanced laboratories, observatories, data collections, and computational centers, and of which Eurovolc (www.eurovolc.eu) represents a valuable example. Other successful sharing initiatives include the VOBP (Volcano Observatory Best Practices) workshop series aimed at sharing best practices for volcano observatories, and including sharing of resources to sustain the inclusion of observatories from developing countries (Pallister et al. 2019).

The talk at AGU 2020 focused on the expected major developments in the current decade 2020-2030. Identifying the many sectors of volcanology that may benefit from significant advance is beyond the scope. The aim there, and here with this short paper, was that of identifying some major elements that may contribute significantly to shape volcanology in the next years. Together with the contributions from many other colleagues in this volume, the objective is to present a picture of what volcano science may look like in 10 years from now. The perspective that we present here largely (but not exclusively) refers to examples from 
Table 1 The backward and forward perspectives on major developments in volcano science that we (PP) presented at AGU 2010 and 2020

\begin{tabular}{|c|c|c|c|}
\hline Perspective & Decade & Approach & Themes* \\
\hline \multirow[t]{3}{*}{ Backward (in 2010) } & $70 \mathrm{~s}$ & Largely descriptve & Stratigraphy and mapping, field measurements, petrology \\
\hline & $80 \mathrm{~s}$ and $90 \mathrm{~s}$ & Quantification & $\begin{array}{l}\text { Lab measurements and experiments, numerical modeling, geo- } \\
\text { physical surveys }\end{array}$ \\
\hline & $2000-2010$ & Instruments & Multi-parametric space-time series, real-time volcano monitoring \\
\hline \multirow[t]{2}{*}{ Forward (in 2010 and 2020) } & $2010-2020$ & $\begin{array}{l}\text { Statistics and probability } \\
\text { Sharing }\end{array}$ & $\begin{array}{l}\text { Uncertainties, hazards, forecasts } \\
\text { Data, infrastructures, practices }\end{array}$ \\
\hline & $2020-2030$ & Big science & Large infrastructures, large simulation capacity, big data \\
\hline
\end{tabular}

*Each theme existed before the decade indicated here, and it continued to flourish (as it will likely do in the future) in the subsequent decades. Our intention here is uniquely that of trying to identify some of the themes that burst or thrived during each decade, contributing papers and conference presentations and triggering new and substantial discussion in the volcano community

Europe, that we believe can be representative of developments at international scale.

\section{Big science and volcano science}

The key word describing major upcoming developments in volcanology is big science. Big science usually refers to large scientific endeavors involving big budgets, big staff, big machines, and big laboratories. Other communities have engaged in big science since long, with enormous impacts such as those brought by the Large Hadron Collider in particle physics, the Hubble telescope in astronomy and astrophysics, or the large-scale initiative represented by the Human Genome Project (https://www. genome.gov/human-genome-project) in life sciences. ODP (Oceanic Drilling Program) activities carrying out exploration of the ocean floor are an example of large-scale projects in the Earth sciences, which have also largely benefited volcanology especially when the research involved volcanic ridges and arcs. One may wonder whether volcano science needs similar large-scale, international cooperative efforts. As a matter of fact, we are deeply convinced of the unique importance of science developed by individual or small groups of researchers. Examples of deep scientific innovation following from modest funding are countless, and, fortunately, science still flourishes on great ideas. It is a fact, however, that some extraordinary achievements strictly require similar extraordinary investments. The standard model of quantum mechanics constituting our current vision of the world would not be the same, without extreme technological implementations at a few large particle accelerators. Similarly, we would not have machines on Mars sending back pictures and data and possibly preparing a next human mission, without the huge investments that such an endeavor requires.

What about volcanoes? Of all the extremes that we have reached so far, none is as close to us yet as hidden and mysterious as real magma below volcanoes. We send probes to directly observe, sample, and analyze the surface of Mars at a distance of order $10^{8} \mathrm{~km}$, but have never done the same for magma at just $10^{\circ} \mathrm{km}$ below our feet. If curiosity and pure scientific interest are not enough, then it can be noticed that at least 800,000 people in the world live close enough to active volcanoes to directly suffer from a volcanic eruption (UNISDR 2015), and anticipating the occurrence of an eruption strictly requires understanding the nature of magma and its underground dynamics. If one would rank relevance on economic value, then it is useful to recall the immense heat associated with volcanic intrusions, of which the proportion converted into energy at geothermal power plants is nothing but a vanishing fraction (e.g., Friðleifsson and Elders 2005; Tester et al. 2006; Reinsch et al. 2017), as well as the potential of underground brines related to magmatic intrusions to be sources of strategic metals (Blundy et al. 2021). Summed up with renewable and clean characteristics of geothermal energy may make the search for real magma a highly remunerative effort in the near future.

In the talk at AGU 2020, the focus was on three themes that we expect are going to represent big developments in volcanology: directly reaching underground magma; collecting and processing volcanic data at unprecedented level; and developing a global volcano model. Ultimately, those themes can be reduced to measuring, analyzing, and modeling, making up the fundamental components of scientific investigation. Current and foreseen developments are described mostly with reference to ongoing or next initiatives in the European research landscape, of size and breath such as to likely represent big directions for developments also at the global scale.

\section{Krafla Magma Testbed (KMT)}

If one had to fix a date for the initiation of KMT, that would almost certainly be September 2014, when the first dedicated workshop took place within the Krafla caldera. 
That resulted from John Eichelberger's vision and determination, as well as from the openness of Landsvirkjun, the Icelandic energy company owning the Krafla geothermal power plant and hosting the workshop. The story began, however, 5 years earlier, when the drill rig at the IDDP-1 well, aiming at supercritical fluids at 4-km depth, got stuck for days at only $2.1 \mathrm{~km}$ before it was realized that rhyolitic melt had been unexpectedly hit (Elders et al. 2014; Rooyakkers et al. 2021). Retrospectively, it was then realized that buried magma had been encountered a few other times at the same depth while drilling at various locations inside the caldera (Eichelberger 2019). Seismic imaging (Schuler et al. 2015) suggests that the rhyolitic melt may have a minimum volume around $0.5 \mathrm{~km}^{3}$. Flow testing at IDDP-1, before the well casing collapsed, produced an amazing 15-40 $\mathrm{MW}_{\mathrm{e}}$ (Axelsson et al. 2013), suggesting that two such wells would be enough to replace the entire Krafla power plant including a few tens conventional geothermal wells.

The serendipitous encounter with magma at Krafla demonstrates that (i) shallow magma bodies can escape even the most sophisticated geophysical prospections, a fact that is alarming for many high risk volcanoes; and (ii) drilling to magma can be safe, as any known accidental case, including those at Puna, Hawaii, and Menengai caldera, Kenya, did not lead to uncontrolled events (Eichelberger 2020; Rooyakkers et al. 2021).

Today, a large scientific consortium is engaging with country governments and industrial partners to define a long-term program named Krafla Magma Testbed, or KMT (www.kmt.is). KMT is foreseen to be the first underground magma observatory in the world, in the form of a series of long-standing wells for scientific and industrial exploration, directly opening inside and around the shallow magmatic body and equipped with advanced monitoring instrumentation (Fig. 1). Scientific fields opening to next level investigation include the origin of rhyolitic magmas in basaltic environments (and ultimately, the origin of continents), the thermo-fluid dynamics and petro-chemical evolution of magmas, the heat and mass exchange with the plumbing system, surrounding rocks and geothermal system, the rheology and thermo-mechanical properties from deep volcanic rock layers to magma and across the melt-rock interface, the relationships between surface records and deep magma dynamics and interpretation of volcanic unrests, and many others. Decades of speculation that still dominates the scientific debate would be overcome by direct evidence and measurements, and by real-scale experiments on the natural system. Similarly,

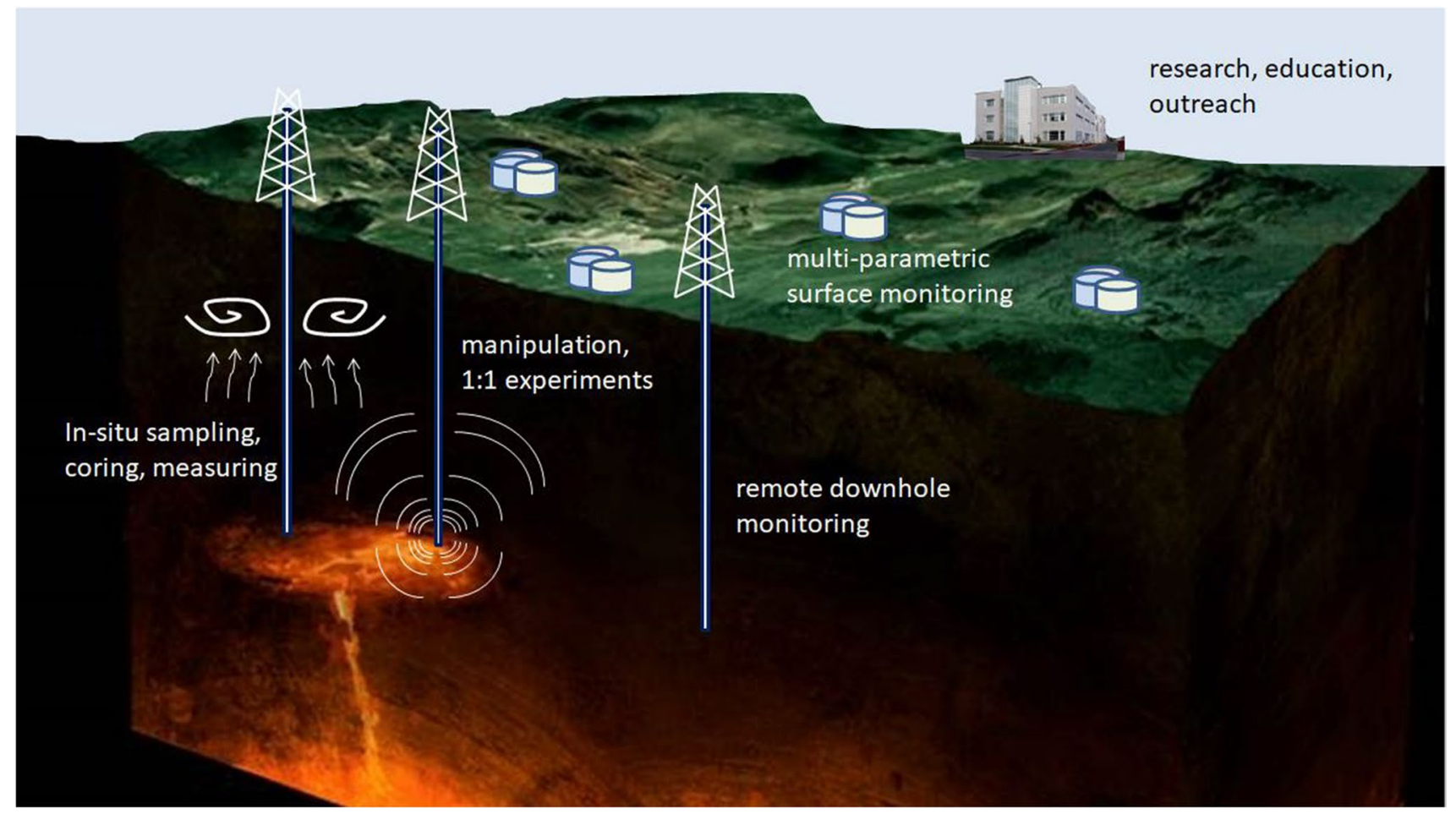

Fig. 1 The KMT concept. A series of wells are kept open inside and around the shallow magma intrusion at Krafla $(2.1 \mathrm{~km}$ depth). Temperature- and corrosion-resistant instrumentation is placed inside the wells down to magma. The surface is heavily instrumented with an advanced multi-parametric monitoring network. Dedicated laboratories, offices, and a visitor center complement the infrastructure. Background picture: courtesy of GEORG (Geothermal Research Cluster of Iceland) 
innovative experimentation and measurements could lead to next-generation geothermal energy production systems exploiting extremely efficient, very high enthalpy nearmagma fluids and heat directly released from the cooling margins of the magma body.

KMT is, obviously, an endeavor that cannot be faced by a restricted group or a single country. It requires instead a large, coordinated effort involving many diverse expertise and capacities from scientific to industrial, and disciplines embracing from thermo-fluid dynamics and material science to geology, geochemistry, and geophysics. The challenges are such as to require coordinated investments of order $10^{8}$ dollars (see www.kmt.is), not little money but still much less than the costs of other large infrastructures mentioned above. Currently (October 2021), the Icelandic government is welcoming partners and dedicating resources; a KMT/ ICDP project has been recently approved; national and international projects raised in support of KMT are saturating the costs for the KMT preparatory phase 0 , and phase 1 involving the first scientific well reaching to magma is getting closer.

\section{Global Volcano Simulator (GVS)}

The atmospheric scientists have been developing for decades general circulation models and a global simulation approach to atmospheric dynamics that they employ daily to produce weather forecasts. While the physics governing volcanic processes is of comparable complexity (e.g., Sparks 2003; Segall 2019; Papale 2021), a large part of the volcanic system is not directly observed (see the KMT description above). That makes a huge difference in terms of quality and accuracy, as atmospheric model predictions can be updated in real time with data coming from below (ground-based), from inside (weather balloons and rockets, radars) and from above (satellites). Similar capacities in volcano science exist for the atmospheric dispersion of volcanic ashes (e.g., Stohl et al. 2011; Tanaka and Iguchi 2019; Pardini et al. 2020), and for other sufficiently slow surface phenomena, such as lava flows (e.g., Wright et al. 2008; Vicari et al. 2011; Bonny and Wright 2017). For the complex dynamics of volcanic unrest and escalation to eruption or return to quiet conditions, which are of utmost relevance for volcano early warning systems and implementation of emergency plans, we are limited to indirect observations through multi-parametric monitoring networks. Those networks provide a rich basis over which the deep volcano dynamics are inferred and the short-term evolutions are forecasted. Still, such forecasts suffer from the lack of a global reference model for their interpretation, often resulting in discordant inferences and projections by different groups of experts.
A reference Global Volcano Simulator would allow many different observations to be placed within a unique, consistent physical framework and integrated holistic dynamic modeling approach. Such a framework should allow a physical representation of the coupled processes and dynamics in multiple domains from the volcanic plumbing system to the surface, including the surrounding rocks and geothermal circulation systems through which signals of deep dynamics are transported to our monitoring networks. Together with the KMT initiative described above and providing groundtruth constraints as well as a unique chance for validation tests, such a global approach to the underground (and surface) volcano dynamics would project volcanology fully into the third millennium, bringing it closer to other scientific fields for which the quantitative revolution started much in advance. The large destination Earth initiative by the European Commission (https://digital-strategy.ec.europa.eu/en/ policies/destination-earth) aims at developing a high precision digital model of the Earth to monitor and simulate both natural and man-made phenomena and processes. The initiative provides a long-term perspective which develops largely through the construction of digital twins (Fig. 2), that is, digital replicas of natural (physical, biological) or man-made systems. Among the high priority digital twins that are foreseen by the Commission, the one on weatherinduced and geophysical extremes (https://digital-strategy. ec.europa.eu/en/library/workshops-reports-elements-digitaltwins-weather-induced-and-geophysical-extremes-and-clima te) is expected to provide the conditions for bringing to a next level some of the recent developments in modeling the complex dynamics of volcanic systems and improving the performance of parallel computing in solid Earth (see also the European Centre of Excellence ChEESE: https://cheesecoe.eu). As a matter of fact, the digital twin concept applied to volcanoes coincides largely with the GVS described here, showing that the times can be mature for such an ambitious undertaking.

\section{Big volcano data}

Direct observations and global modeling described above are expected to impact deeply volcano science. The fundamental source of information on volcanic processes and dynamics from most volcanoes worldwide will continue to be the multi-parametric remote and on-site instrumental networks collecting data before, during, and after volcanic eruptions. With the development of the digital age, big data and related technologies such as Machine Learning (ML) and artificial intelligence (AI) have exploded in virtually any aspect of science (e.g., Chen et al. 2012; Wamba et al. 2015; Gorelick et al. 2017). AI algorithms can be trained to reproduce some of our capabilities, 


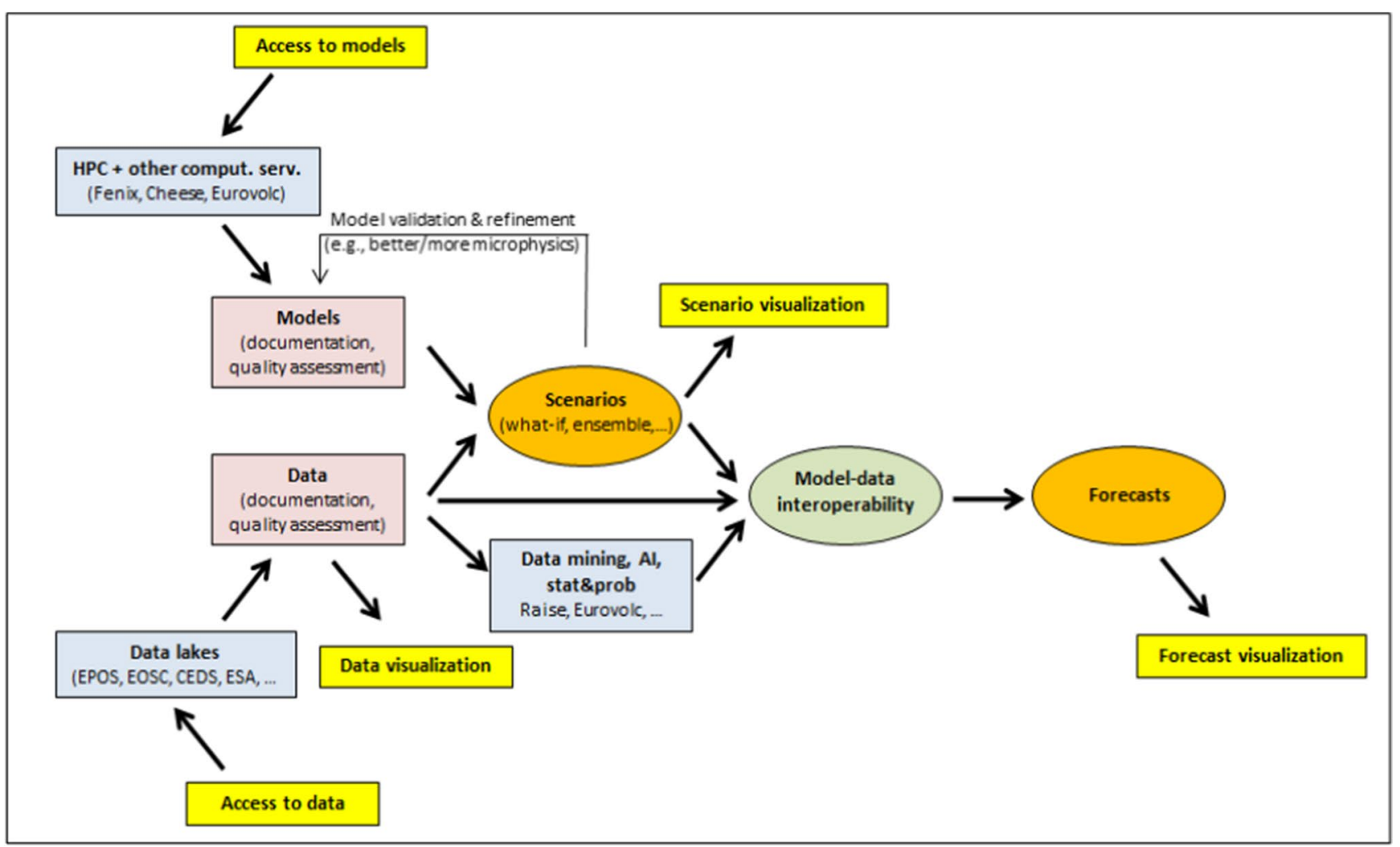

Fig. 2 Possible scheme for a digital twin of a volcanic system. Models and data concur to scenarios and forecasts. Models are continuously tested and refined, e.g., by adding more or better microphysics. Both data and models are accompanied by quality assessments and certification. Third parties access data and models, as well as visualization tools. While the scheme is general, the cited resources refer to the European landscape

are organized and accessible through space agencies, with increasing levels of accessibility being provided through large-scale initiatives, such as GEO's Geohazard Supersites and Natural Laboratories (https://geo-gsnl. org/). However, a similar level of organization is still missing for ground-based data collected at volcanoes worldwide. Relevant attempts to provide free, organized access to ground-based volcano data are ongoing (e.g., Newhall et al. 2017; Costa et al. 2019; in Japan: Ueda et al. 2019; in Europe: Bailo and Sbarra 2017; etc.), while large funding agencies such as the European Union (https://ec.europa.eu/info/research-and-innovation/strat egy/strategy-2020-2024/our-digital-future/open-science en; https://ec.europa.eu/info/sites/default/files/turning fair_into_reality_0.pdf) increasingly require strict adherence to the principles of open science and FAIR data. Definitely, of all the projections one may make for volcano science in the next decade, the one with the highest likelihood of revealing correct is the burst of big volcano data, or otherwise, volcano science would find itself lagging behind other communities who fully profit of big developments that will largely shape research and support scientific advance in the coming years and decades. tinuous streams of space-time data daily. Satellite data 


\section{Concluding remarks}

The volcanological community has been capable of benefiting from substantial infrastructural developments, for example in relation to satellite missions. Even in such cases, however, volcanologists have taken advantage from missions dedicated to other objectives, such as those related to weather forecasts, climate change, or land evolution. Still, the benefits from a "big science" approach in volcanology appear substantial in terms of mitigated risks and increased security on one side, and potential for efficient, clean, and renewable energy on the other side. In comparison, order of magnitude larger funds dedicated to space exploration, while expanding greatly our fundamental understanding of the Universe, does not seem to bring comparable practical benefits, at least over the short-medium time scale.

Decades of volcano science clearly show that major volcanic eruptions in terms of their size or impacts not only have been big drivers for scientific advance, they also have focused substantial attention by the governments, the media, and the public. However, the momentum gets easily lost, and after an initial promising phase of increased funding opportunities, often volcanoes quickly slip backwards in the priority list. As a volcanological community, we may need to improve our capability to stay on the scene, e.g., by transposing our scientific endeavors into effective narratives which tell of the exciting travel towards unexplored frontiers of our planet Earth, at the same time increasing security and contributing to sustainability and preservation of the delicate equilibria of the planet.

Acknowledgements A perspective paper is obviously the result of many years of interactions with colleagues having similar or different, sometimes even diverging, views on what our science misses mostly or mostly benefits from. To all of these colleagues, we are grateful, as literally each of them had much to teach us. We are also grateful to Mike Poland and Steve Sparks who reviewed the manuscript and improved it through many insightful comments and suggestions. One of us (DG) benefited from a grant by EPOS-IT.

Open Access This article is licensed under a Creative Commons Attribution 4.0 International License, which permits use, sharing, adaptation, distribution and reproduction in any medium or format, as long as you give appropriate credit to the original author(s) and the source, provide a link to the Creative Commons licence, and indicate if changes were made. The images or other third party material in this article are included in the article's Creative Commons licence, unless indicated otherwise in a credit line to the material. If material is not included in the article's Creative Commons licence and your intended use is not permitted by statutory regulation or exceeds the permitted use, you will need to obtain permission directly from the copyright holder. To view a copy of this licence, visit http://creativecommons.org/licenses/by/4.0/.

\section{References}

Anantrasirichai N, Biggs J, Albino F, Bull D (2019) The application of convolutional neural networks to detect slow, sustained deformation in InSAR time series. Geophys Res Lett 21:11850-11858

Anantrasirichai N, Biggs J, Albino F, Hill P, Bull D (2018) Application of machine learning to classification of volcanic deformation in routinely generated InSAR data. J Geophys Res Solid Earth 123:6592-6606

Axelsson G, Egilson T, Gylfadottir SS (2013) Modelling of temperature conditions near the bottom of well IDDP-1 in Krafla. Northeast Iceland Gothermics 49:49-57

Bailo D, Sbarra M (2017) EPOS - European Plate Observing System: applying the VRE4EIC virtual research environment model in the solid Earth science domain. ERCIM News 109:13-14

Blundy J, Afanasyev A, Melnik O, Tattitch B, Sparks RSJ, Utkin I (2021) The economic potential of copper-bearing sub-volcanic brines. Royal Soc Open Sci 8:202192

Bolton MSM, Jensen BJL, Wallace K, Praet N, Fortin D, Kaufman D, De Batist M (2020) Machine learning classifiers for attributing tephra to source volcanoes: an evaluation of methods for Alaska tephras. J Quat Sci 35(1-2):81-92. https://doi.org/10. 1002/jqs.3170

Bonny E, Wright R (2017) Predicting the end of lava flow-forming eruptions from space. Bull Volcanol 79:52. https://doi.org/10. 1007/s00445-017-1134-8

Bueno A, Zuccarello L, Díaz-Moreno A, Woollam J, Titos M, Benítez C, Álvarez I, Prudencio J, De Angelis S (2020) PICOSS: Python interface for the classification of seismic signals. Comp Geosci 142:104531

Chen H, Chiang RHL, Storey VC (2012) Business intelligence and analytics: from big data to big impact. MIS Q 36(4):1165-1188

Corradino C, Ganci G, Cappello A, Bilotta G, Calvari S, Del Negro C (2020) Recognizing eruptions of Mount Etna through machine learning using multiperspective infrared images. Remote Sens 12:970. https://doi.org/10.3390/rs12060970

Costa F, Widiwijayanti C, Nang TZW, Fajiculay E, Espinosa-Ortega T, Newhall C (2019) WOVOdat - The global volcano unrest database aimed at improving eruption forecasts. Disaster Prevent Managem 28:6

Eichelberger J (2019) Magma: a journey to inner space. Eos 100:27-31

Eichelberger J (2020) Distribution and transport of thermal energy within magma-hydrothermal systems. Geosciences 10(6):212

Elders WA, Friðleifsson GÓ, Albertsson A (2014) Drilling into magma and the implications of the Iceland Deep Drilling Project (IDDP) for high-temperature geothermal systems worldwide. Geothermics 49:111-118. https://doi.org/10.1016/j.geothermics.2013.05.001

Friðleifsson GO, Elders WA (2005) The Iceland Deep Drilling project: a search for deep unconventional geothermal resources. Geothermics 34:269-285. https://doi.org/10.1016/j.geothermics.2004.11. 004

Gorelick N, Hancher M, Dixon M, Ilyushchenko S, Thau D, Moore R (2017) Google Earth engine: planetary-scale geospatial analysis for everyone. Remote Sens Env 202:18-27

Hajian A, Cannavò F, Greco F, Nunnari G (2019) Classification of Mount Etna (Italy) volcanic activity by machine learning approaches. Ann Geophys 62(2):VO231. https://doi.org/10.4401/ ag-8049

Malfante M, Dalla Mura M, Metaxian J-P, Mars JI, Macedo O, Inza A (2018) Machine learning for volcano seismic signals: challenges and perspectives. IEEE Signal Proc Mag 35(2):20-30

Masotti M, Falsaperla S, Langer H, Spampinato S, Campanini R (2006) Application of support vector machine to the classification 
of volcanic tremor at Etna. Italy Geophys Res Lett 33:L20304. https://doi.org/10.1029/2006GL027441

Newhall CG, Costa F, Ratdomopurbo A, Venezky DY, Widiwijayanti C, Nang Thin Zar Win, Tan K, Fajiculay E (2017) WOVOdat - an online, growing library of worldwide volcanic unrest. J Volcanol Geotherm Res 345:184-199. https://doi.org/10.1016/j.jvolgeores. 2017.08.003

Pallister J, Papale P, Eichelberger J, Newhall C, Mandeville C, Nakada S, Marzocchi W, Loughlin S, Jolly G, Ewert J, Selva J (2019) Volcano observatory best practices (VOBP) workshops - a summary of findings and best-practice recommendations. J Appl Volcanol 8:2. https://doi.org/10.1186/s13617-019-0082-8

Papale $\mathrm{P}$ (2021) Some relevant issues in volcanic hazard forecasts and management of volcanic crises. In: Volcanic hazards, risks, and disasters, volume 2. Elsevier. 1-24 (ISBN: 978-0-12-818082-2)

Pardini F, Corradini S, Costa A, EspostiOngaro T, Merucci L, Neri A, Stelitano D, de VitturiMichieli M (2020) Ensemble-based data assimilation of volcanic ash clouds from satellite observations: applications to the 24 December $2018 \mathrm{Mt}$. Etna explosive eruption. Atmosphere 11:359. https://doi.org/10.3390/atmos11040359

Parra J, Fuentes O, Anthony E, Kreinovich V (2017) Use of machine learning to analyze and - hopefully - predict volcano activity. Acta Polit Hung 14:3

Pignatelli A, Piochi M (2021) Machine learning applied to rock geochemistry for predictive outcomes: the Neapolitan volcanic history case. J Volcanol Geotherm Res 415:107254

Reinsch T, Dobson P, Asanuma H, Huenges E, Poletto F, Sanjuan B (2017) Utilizing supercritical geothermal systems: a review of past ventures and ongoing research activities. Geotherm Energy 5:16. https://doi.org/10.1186/s40517-017-0075-y

Rooyakkers SM, Stix J, Berlo K, Petrelli M, Sigmundsson F (2021) Eruption risks from covert silicic magma bodies. Geology 49:921-925

Segall P (2019) Magma chambers: what we can, and cannot, learn from volcano geodesy. Phys Eng Sci 377(2139):20180158

Sparks RSJ (2003) Forecasting volcanic eruptions. Earth Planet Sci Lett 210:1-15

Schuler J, Greenfield T, White RS, Roecker SW, Brandsdóttir B, Stock JM, Tarasewicz J, Martens HR, Pugh D (2015) Seismic imaging of the shallow crust beneath the Krafla central volcano, NE Iceland. J Geophys Res Solid Earth 120:7156-7173. https://doi.org/ 10.1002/2015JB012350
Stohl A, Prata AJ, Eckhardt S, Clarisse L, Durant A, Henne S, Kristiansen NI, Minikin A, Schumann U, Seibert P, Stebel K, Thomas HE, Thorsteinsson T, Tørseth K, Weinzierl B (2011) Determination of time- and height-resolved volcanic ash emissions and their use for quantitative ash dispersion modeling: the 2010 Eyjafjallajökull eruption. Atmos Chem Phys 11:4333-4351. https://doi.org/10. 5194/acp-11-4333-2011

Tanaka HL, Iguchi M (2019) Numerical simulations of volcanic ash plume dispersal for Sakura-Jima using real-time emission rate estimation. J Disaster Res 14(1):160-172

Tester JW, Anderson BJ, Batchelor AS, Blackwell DD, DiPippo R, Drake EM, Garnish J, Livesay B, Moore MC, Nichols K, Petty S, Toksöz MN, Veatch, Jr RW (2006) The future of geothermal energy in the 21 century impact of enhanced geothermal systems (EGS) on the United States. Cambridge: MIT Press (MA). https:// energy.mit.edu/wp-content/uploads/2006/11/MITEI-The-Futureof-Geothermal-Energy.pdf

Ueda H, Yamada T, Miwa T, Nagai M, Matsuzawa T (2019) Development of a data sharing system for Japan volcanological data network. J Disaster Res 14:571-579

UNISDR (2015) Making development sustainable: the future of disaster risk management. Global assessment report on disaster risk reduction (United Nations Office for Disaster Risk Reduction, Geneva, Switzerland

Vicari A, Ganci G, Behncke B, Cappello A, Neri M, Del Negro C (2011) Near-real-time forecasting of lava flow hazards during the 12-13 January 2011 Etna eruption. Geophys Res Lett 38:L13317. https://doi.org/10.1029/2011GL047545

Wamba SF, Akter S, Edwards A, Chopin G, Gnanzou D (2015) How big data can make big impact: findings from a systematic review and a longitudinal case study. Int J Prod Econ 165:234-246

Watson LM (2020) Using unsupervised machine learning to identify changes in eruptive behavior at Mount Etna, Italy. J Volcanol Geotherm Res 405:107042

Witsil AJC, Johnson JB (2020) Analyzing continuous infrasound from Stromboli volcano, Italy using unsupervised machine learning. Comp Geosci 140:104494

Wright R, Garbeil H, Harris AJL (2008) Using infrared satellite data to drive a thermo-rheological/stochastic lava flow emplacement model: a method for near-real-time volcanic hazard assessment. Geophys Res Lett 35(19):L19307 